\title{
NUMERICAL MODELLING OF MASONRY ARCHES STRENGTHENED WITH SFRM
}

\section{S. CADDEMI ${ }^{1}$, I. CALIÒ ${ }^{1}$, F. CANNIZZARO ${ }^{1}$, D. RAPICAVOLI $^{1}$, N. SIMONCELLO ${ }^{2}$, P. ZAMPIERI ${ }^{2}$, J. GONZALEZ-LIBREROS ${ }^{3}$, C. PELLEGRINO ${ }^{2}$,}

${ }^{1}$ Department of Civil Engineering and Architecture, University of Catania, Via Santa Sofia 64, 95125 Catania, Italy.

${ }^{2}$ Department of Civil, Environmental and Architectural Engineering, University of Padua, Via Marzolo 9, 35131 Padua, Italy.

${ }^{3}$ Department of Civil, Environmental and Natural Resources Engineering, Lulea University of Technology, 97187 Lulea, Sweden.

paolo.zampieri@dicea.unipd.it, (Paolo Zampieri)

Keywords: Masonry arch; Fiber reinforced mortar; steel fibers, discrete macro-element model; HiStrA software, nonlinear static analysis

\begin{abstract}
The adoption of effective strengthening techniques of historical constructions is one of the most widely debated aspects in structural engineering. Within this topic, the application of steel fiber reinforced mortar (SFRM) has been recently proposed as a low invasive and effective way to obtain a considerable structural benefit in the safety of existing masonry structure. To this purpose, in this paper the experimental results obtained on a circular masonry arches are presented. The considered specimens, subjected to a vertical increasing static load, is tested in the unstrengthened and strengthened configurations, and is part of a wider experimental campaign. After presenting and discussing the experimental results, they are compared with those relative to numerical simulations conducted by means of a discrete macroelement (DME) strategy, based on a simple mechanical scheme, able to model the nonlinear behavior of masonry structures with a limited computational effort. Such an approach is here extended to model the SFRM strengthening technique accounting for the main failure mechanisms associated to the combined presence existing masonry and the additional strengthening layer applied at the intrados of the arch. Numerical and experimental results demonstrate the efficacy of the proposed retrofitting strategy both in terms of bearing capacity and increase of ductility.
\end{abstract}




\section{INTRODUCTION}

Masonry arch bridges still in use in the world roadway and railway network represent an important portion of the entire bridge stock and most of them were built more than 100 years ago. Due to their age, the restoration and the conservation of masonry bridge is an important aim of the infrastructure's owners. In many cases, a repair intervention is needed in order to bring the bridge to an adequate structural safety level required by National Standards. Different actions are responsible of the decrement of the structural safety level of the masonry arch bridges; for example: the increased traffic loads, the environmental actions, soil settlements, lack of maintenance, seismic events, etc... Many (traditional and innovative) strengthening techniques [1,5] have been investigated by scientific community with the aim to repair/maintenance masonry bridges.

Recently, the use of reinforced mortar with short steel fibers as strengthening system applied to concrete or masonry has caught the attention of many researchers. In fact, this composite material has high value of compressive and tensile strengths with a good tensile ductility due to the steel fibers.

In this paper, the effectiveness of steel fiber reinforced mortar (SFRM) for the strengthening of masonry arches is evaluated. A masonry arch previously loaded in order to achieve a specified damage level, was strengthened with a SFRM layer at the intrados and then retested [3]. Numerical simulations have been performed in order to describe the non-linear behavior of the masonry arch in unstrengthened and strengthe a discrete macro-model, already available in
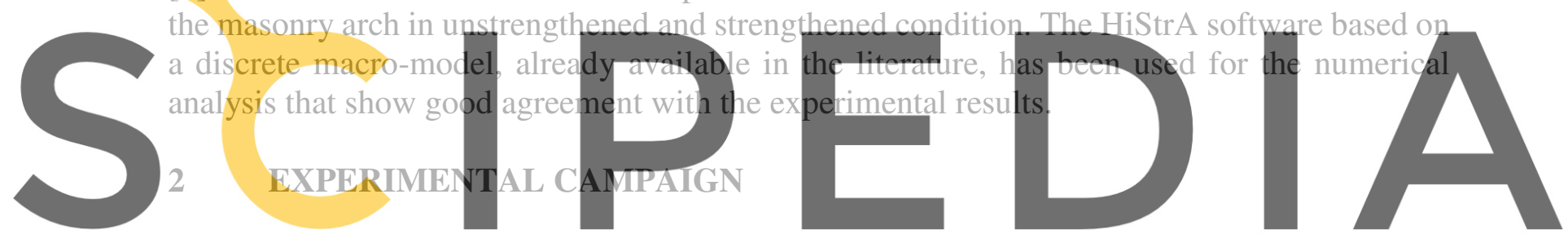

A single masonry arch (Fig. 1) was tested (UN.ND) under a monotonic force concentrated

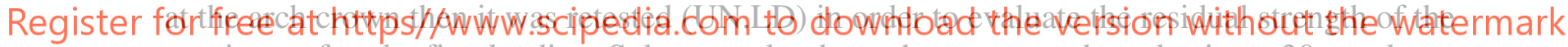
specimen after the first loading. Subsequently, the arch was strengthened using a $30 \mathrm{~mm}$ layer of SFRM (Fig. 2) applied at the arch intrados and it was tested again (SFRM.LD).

The arch specimen was comprised of 29 clay bricks disposed in a single layer. The arch rise (f), span length (L), thickness (S), and width (W) were $610 \mathrm{~mm}, 1430 \mathrm{~mm}, 110 \mathrm{~mm}$, and $245 \mathrm{~mm}$, respectively as reported in Fig. 1. Standard clay bricks were used in this investigation with nominal dimensions equal to $245 \times 110 \times 60 \mathrm{~mm}$.

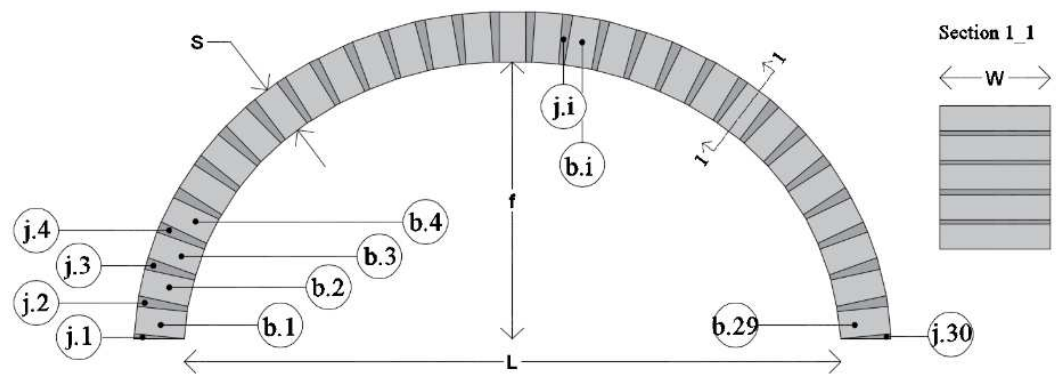

Figure 1. Arch geometry and brick-joint numbering. 
A low strength cementitious mortar was used for the arch joints in order to replicate the current condition of existing arches. Standard clay bricks were used in this investigation with nominal dimensions equal to $245 \times 110 \times 60 \mathrm{~mm}$. The SFRM is comprised of a high strength mortar fiberreinforced with around $2 \%$ of hook end steel fibers in volume. The mechanical parameters experimentally evaluate are reported in Simoncello et al 2019 [3].

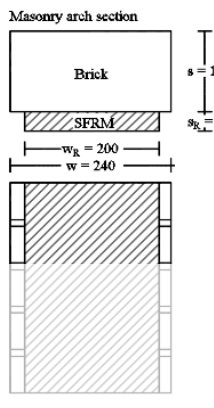

a)

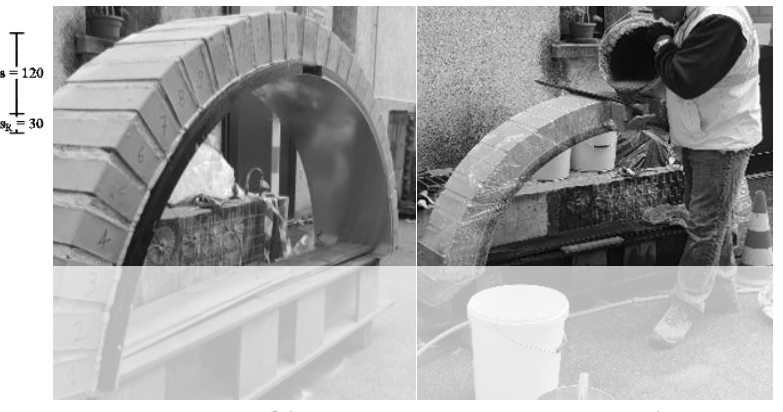

b) c)

Figure 2. Strengthening procedure: a) SFRM dimension, b) Formwork, c) SFRM pouring.

The load was applied through a hydraulic manual jack connected to a load cell with a maximum capacity of $20 \mathrm{kN}$. The

b.15, as shown in Fig.

load until the load drop

failure of the arch was

arch were monitored b

positioned as shown in Fig. 3 .
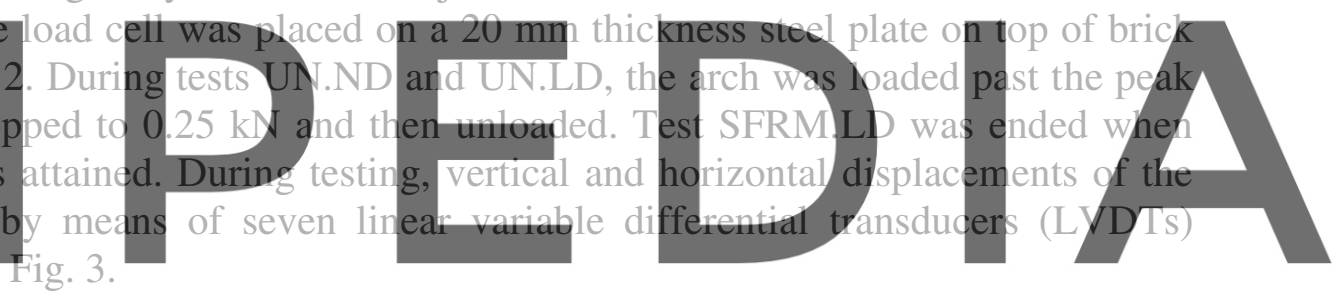

Register for free at https//www.scipedia.com to download the version without the watermark

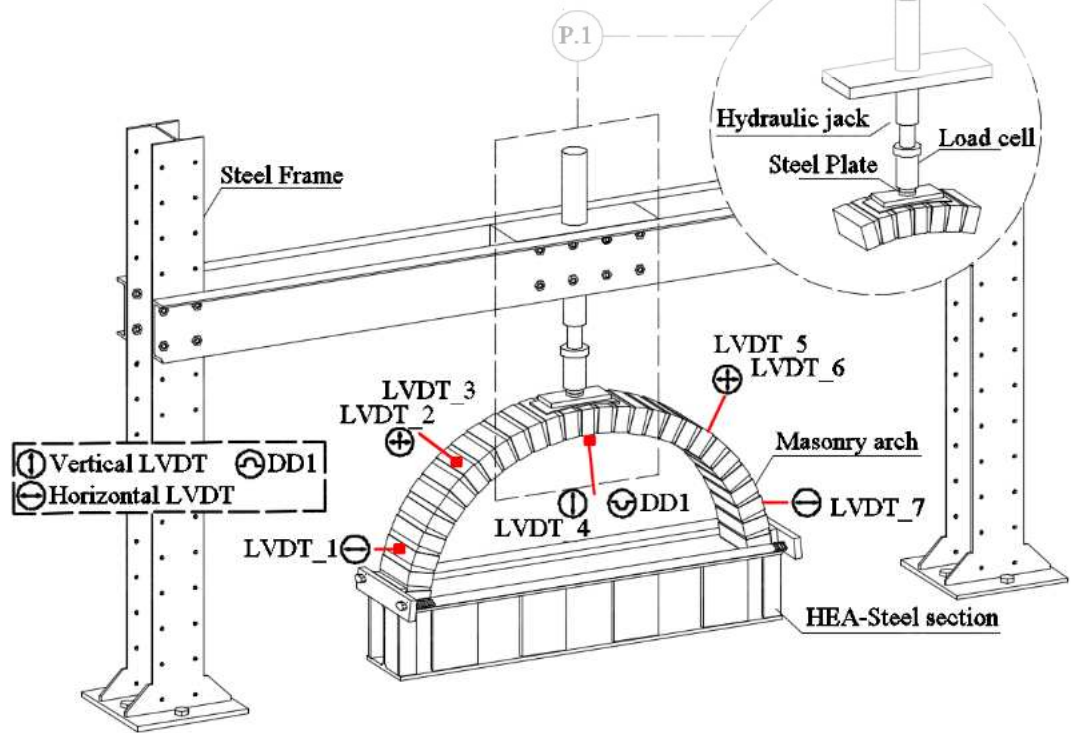

Figure 3. Test setup: applied load system and displacement monitoring. 
In this work a numerical strategy based on a discrete macro-model, already available in the literature, is employed for the nonlinear numerical simulations of the considered dome. According to this approach, the masonry is modeled by an equivalent mechanical scheme constituted by a hinged quadrilateral endowed with one or two diagonal links to rule the diagonal shear cracking, and interacting with contiguous elements along its four edges by means of nonlinear discrete interfaces, which govern the flexional and the sliding behaviour. Each discrete interface is made of a single or multiple (according to the model) rows of transversal links for the flexional behaviour and single or multiple (according to the model) sliding links. The different stages of this discrete element are reported in Figure 4. This approach was originally introduced for modeling the in-plane behavior of unreinforced masonry structures [6] (Figure4a). This plane element possesses four degrees of freedom, a single row of transversal links and a single in-plane sliding link, and is able to model the main failure mechanisms of the masonry in its own plane, as long as a proper calibration procedure of the links is adopted. Two subsequent upgrades were achieved to expand the potentialities of the approach. First, the outof-plane (spatial) behavior, typical of historical constructions, was added [7] by considering additional rows of transversal links and two additional out-of-plane sliding links (able to govern the out of plane shear behaviour and the torsion), thus enabling the out-of-plane degrees of freedom (Figure 4b). Subsequently, a further upgrade was introduced considering a shell macroelement characterized by an irregular geometry, variable thickness along the element and skew interfaces [8] in order to deal with structures with a curved geometry, such as vaults and domes, Figure 4c. The calibrati properly extended in or keeping the same general philosophy. Numerical and experimental validations of the pron historical structures can be found in [9, 10]; a specific study devoted to the investigation of

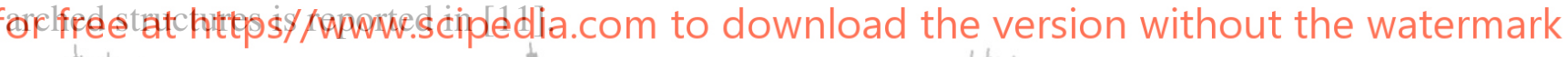

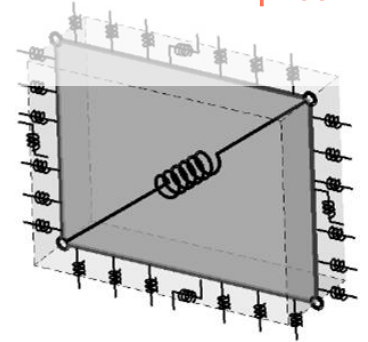

(a)

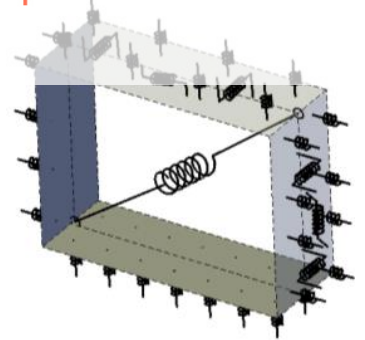

(b)

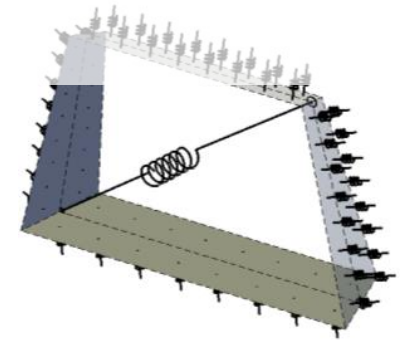

(c)

Figure 4. Layout of the macro-element adopted for masonry at its three stages: (a) plane element, (b) spatial regular element and (c) three-dimensional element for curved structures.

In all the above referenced paper applications in the nonlinear static field where proposed. More recently, the proposed approach has been upgraded to account for the presence of fiberreinforced reinforcements [12], Figure 5. However, none of the studies focused on strengthened structures was devoted to SFRM; in this paper, the proposed methodology is applied for the first time with reference to curved structures reinforced with a SFRM technique. 


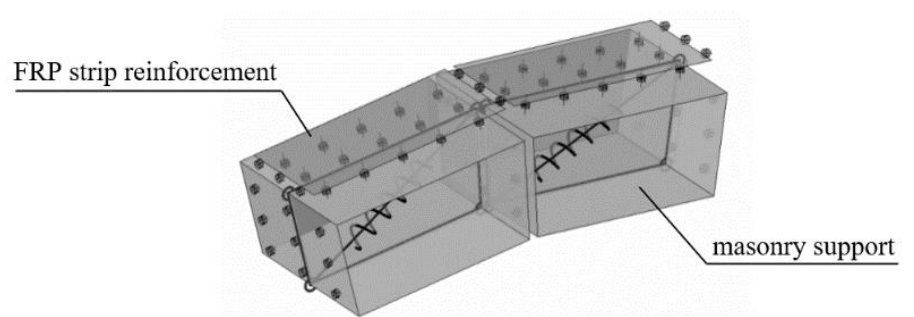

Figure 5. Layout of the interaction between flat FRP discrete element and masonry substrate [9].

\section{COMPARISON BETWEEN EXPERIMENTAL AND NUMERICAL RESULTS}

The maximum load Pmax, the ratio between the test maximum load and that of the test UN.ND (Pmax/Pmax,UN.ND), and ductility for each test are summarized in Table 1. In this paper, the ductility is computed as the ratio between the ultimate displacement (the displacement at ultimate load, taken as $85 \%$ of the maximum load in the descending branch of the applied load vs. arch crown displacement curve) and the displacement at the end of the elastic branch [3].

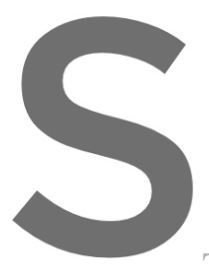

Table 1. Summary of test results.

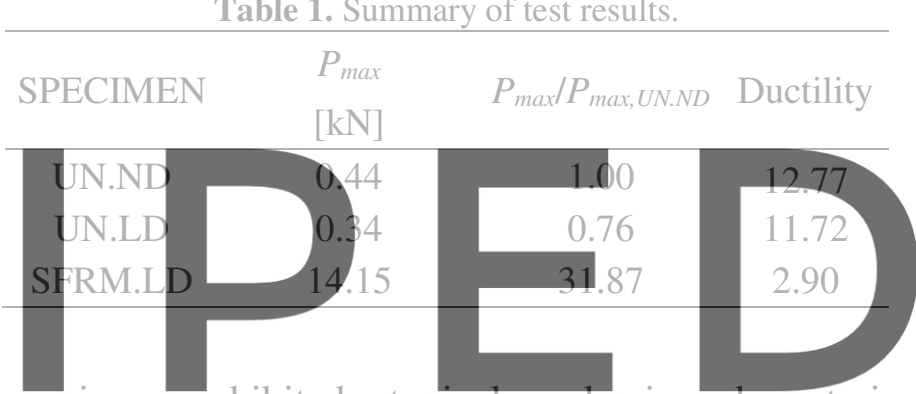

The unstrengthened specimens exhibited a typical mechanism characterized by the formation of four alternate hinges, as shown in Fig. 6. For both tests, the location and sequence of the

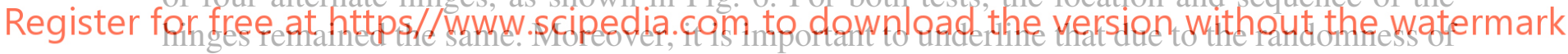
the material the hinge configuration is not symmetrical as well-known from equilibrium theory.

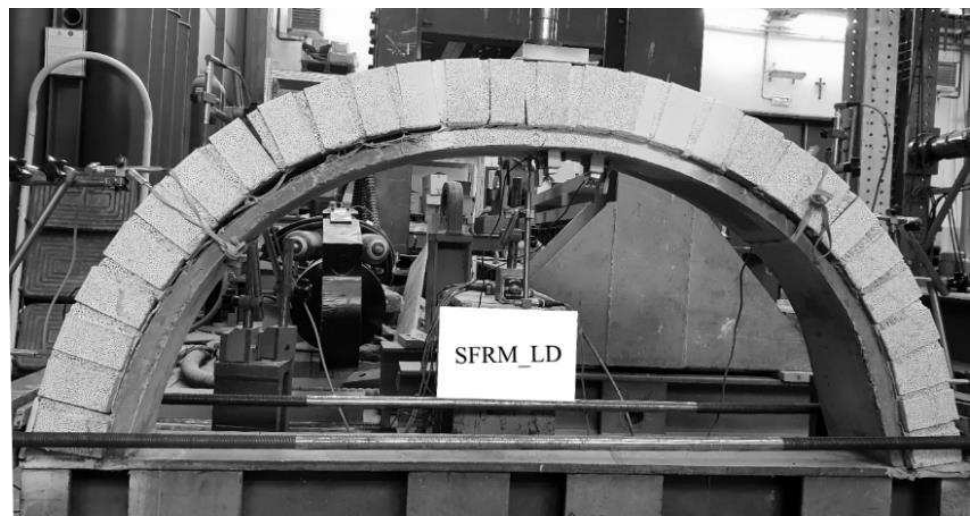

Figure 6. Collapse mechanism for the strengthened condition 
A numerical model was implemented in the software environment HiStrA (Historical Stuctures Analysis) which employs the numerical approach described in the previous section. The model is made of 29 elements (which are associated to 116 inplane degrees of freedom), for which the adopted mechanical properties are summarized in Table 2. In particular, the flexural constitutive law is characterized by the Young's modulus $E$, the compressive $\sigma_{c}$ and tensile $\sigma_{t}$ strengths and the compressive $G_{c}$ and tensile $G_{t}$ fracture energies; the shear diagonal behavior is considered elastic and associated to the shear modulus $G$; no sliding can occur among the blocks.

Table 2. Mechanical properties adopted in the numerical model.

\begin{tabular}{cccccccccc}
\hline Typology & $\begin{array}{c}E \\
{[\mathrm{MPa}]}\end{array}$ & $\begin{array}{c}\sigma_{c} \\
{[\mathrm{MPa}]}\end{array}$ & $\begin{array}{c}G_{c} \\
{[\mathrm{~N} / \mathrm{mm}]}\end{array}$ & $\begin{array}{c}\sigma_{t} \\
{[\mathrm{MPa}]}\end{array}$ & $\begin{array}{c}G_{t} \\
{[\mathrm{~N} / \mathrm{mm}]}\end{array}$ & $\begin{array}{c}G \\
{[\mathrm{MPa}]}\end{array}$ & $\begin{array}{c}c \\
{[\mathrm{MPa}]}\end{array}$ & $\begin{array}{c}G_{s} \\
{[\mathrm{~N} / \mathrm{mm}]}\end{array}$ & $\begin{array}{c}w \\
{\left[\mathrm{kN} / \mathrm{m}^{3}\right]}\end{array}$ \\
\hline $\begin{array}{c}\text { Masonry } \\
\text { arch }\end{array}$ & 1000 & 7.22 & 3 & 0.014 & 0.04 & 400 & - & - & 18 \\
SFRM & 15000 & 91.02 & 1000 & 10 & 5 & 6000 & 0.2 & 0.13 & 24 \\
\hline
\end{tabular}

\section{In Figure 8a, a comparison between numerical and experimental results in terms of capacity} curve, is depicted. The results show a good agreement in terms of initial stiffness, peak load and softening branch. The agreement is encountered also in terms of failure mechanism, Figure $8 \mathrm{~b}$, which is characterized by the opening of five flexural hinges with symmetric locations. The progression of the opening of the flexural hinges is also identified in the capacity curve.
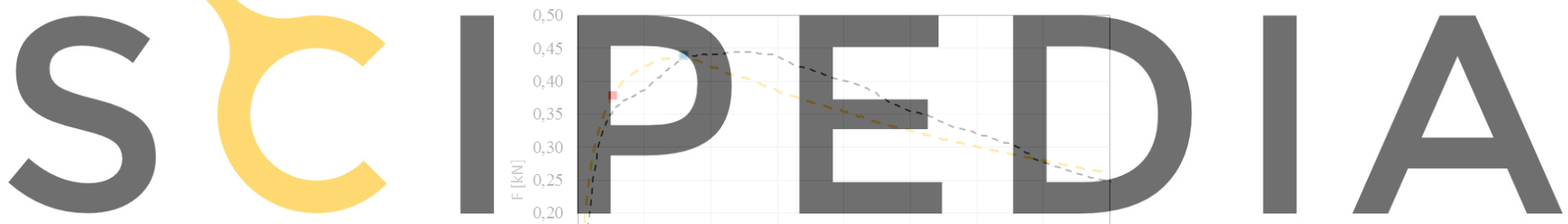

Register for free at https//www.scipedia.com to download the version without the watermark

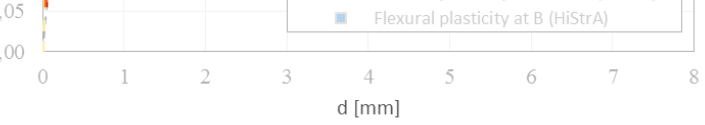

(a)

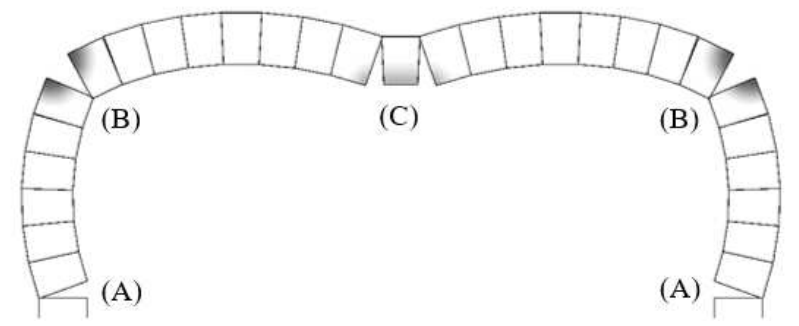

(b)

Figure 8. Numerical results of the unstrengthened arch in terms of a) load-arch crown displacement and b) failure mechanism

Since the thickness of the SFRM strengthening is not negligible with respect to the arch thickness, in the numerical model of the strengthened arch it is modelled with an inner ring of 29 discrete elements, which lead to a total amount of degrees of freedom equal to 232 . The 
inner ring of elements is associated to the mechanical properties reported in Table 2. In particular, the sliding between inner SFRM ring and external masonry arch is enabled and associated to an elastic-plastic behaviour with softening associated to the cohesive strength $c$ and fracture energy $G_{s}$. In Figure 9 the results in terms of capacity curve and failure mechanism are reported; as expected, the failure mechanism involves the sliding between the masonry arch and the SFRM reinforcement, which also delays the opening of the flexural hinges. Again, the sequence of opening of the hinges is summarized in the capacity curve thus allowing to reconstruct the progression of the damage in the arch. The numerical results, which are in good agreement with the experimental ones, are able to grasp the beneficial contribution and the effectiveness of the SFRM technique.
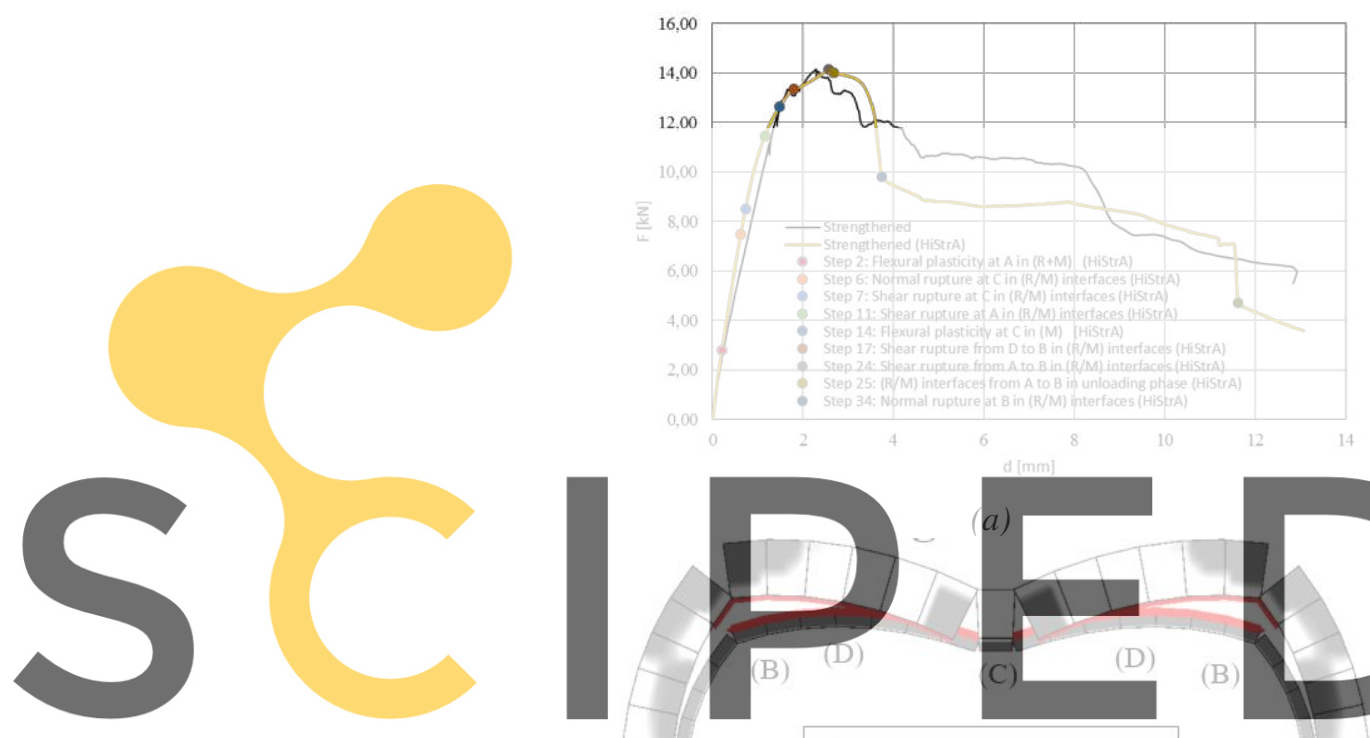

\section{Register for free at https//www.scipedia.com fo downiload the version without the watermark (b)}

Figure 9. Numerical results of the strengthened arch in terms of a) load-arch crown displacement and b) failure mechanism

\section{CONCLUSION}

In this paper, the destructive experimental tests of a masonry arch (in the unstrengthened condition and in the strengthened with SFRM layer applied to arch intrados condition) have been reported. Results show an increase in term of load-carrying capacity of around 40 times respect to the unstrengthened condition. A simplified numerical strategy based on a Discrete Macro-Element approach, previously adopted for modelling masonry structures, and other strengthening techniques, is here applied for the first time to model arches reinforced with SFRM. The numerical simulations, using a HiStrA software based on a discrete macro-model, show the load-arch crown displacement curve with a good agreement respect to the experimental curves. The failure modes as collapse mechanism for the unstrengthened 
condition and the detachment of the SFRM strip for the strengthened condition are in according with the experimental results.

\section{REFERENCES}

[1] D. V. Oliveira, I. Basilio, and P. B. Lourenço, "Experimental Behavior of FRP Strengthened Masonry Arches," J. Compos. Constr., vol. 14, no. 3, pp. 312-322, 2010.

[2] P. Zampieri, N. Simoncelo, C. D. Tetougueni, and C. Pellegrino, "A review of methods for strengthening of masonry arches with composite materials," Eng. Struct., vol. 171, no. May, pp. 154-169, 2018.

[3] Simoncello N, Zampieri P, Gonzalez-libreros J, Pellegrino C. Experimental behaviour of damaged masonry arches strengthened with steel fiber reinforced mortar (SFRM). Comp. Part B 2019; 177:107386. https://doi.org/10.1016/j.compositesb.2019.107386.

[4] Zampieri, P. Horizontal capacity of single-span masonry bridges with intrados FRCM strengthening (2020) Composite Structures, 244, art. no. 112238, . DOI: 10.1016/j.compstruct.2020.112238.

[5] Zampieri, P., Simoncello, N., Gonzalez-Libreros, J., Pellegrino, C. Evaluation of the vertical load capacity of masonry arch bridges strengthened with FRCM or SFRM by limit analysis (2020) Engineering Structures. DOI: 10.1016/j.engstruct.2020.111135

[6] Caliò, I., Marletta, M., and Pantò, B. (2012). A new discrete element model for the evaluation of the seismic behaviour of unreinforced masonry buildings. Eng. Struct. 40, 327 338. doi:10.1016/j.engstruct.2012.02.039
[7] B. Pantò, F. Cannizzaro, I. Caliò, P.B. Lourenço Numerical and experimental validation
of a 3D macro-model for the in-plane and out-of-plane behoviour of unreinforced maspnty
walls - (2017) International. Journal of Architectural Heritage, 11(7), pp.946-964 doi:
10.1080/15583058.2017.1325539.

[8] I. Caliò, F. Cannizzaro, M. Marletta (2010). A discrete element for modeling masonry

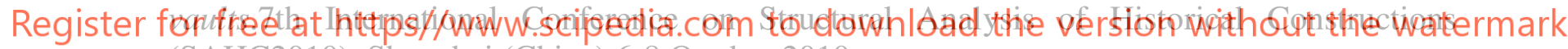
(SAHC2010). Shanghai (China) 6-8 Ottobre 2010.

[9] F. Cannizzaro, P.B. Lourenço, Simulation of Shake Table Tests on Out-of-Plane Masonry Buildings. Part (VI): Discrete Element Approach - (2017) International Journal of Architectural Heritage, 11(1), pp. 125-142 doi: http://dx.doi.org/10.1080/15583058.2016.1238973.

[10] Pantò, B., Cannizzaro, F., Caddemi, S., and Caliò, I. (2016). 3 D macro-element modelling approach for seismic assessment of historical masonry churches. Adv. Eng. Softw. 97, 40-59. doi:10.1016/j.advengsoft.2016.02.009

[11] Cannizzaro, F., Pantò, B., Caddemi, S., and Caliò, I. (2016). A Discrete Macro-Element Method (DMEM) for the nonlinear structural assessment of masonry arches. Eng. Struct. (2018) 168:243-56

[12] Pantò, B., Cannizzaro, F., Caddemi, S., Caliò, I., Chácara, C. and Lourenço, PB., Nonlinear modelling of curved masonry structures after seismic retrofit through FRP reinforcing. Buildings (2017) 7:79. 